\title{
Developing a wireless real-time automated home approach utilizing NI MyRIO microcontroller board and LabVIEW platform
}

\author{
Ahmad A. Alahmadi \\ Department of Electrical Engineering, Faculty of Engineering, Taif University, Kingdom of Saudi Arabia
}

\begin{tabular}{|c|c|}
\hline Article Info & ABSTRACT \\
\hline Article history: & In this paper, a design process and a hardware implementation for a wireless \\
\hline $\operatorname{Rec}$ & real-time home automation system approach based on NI MyRIO \\
\hline & icrocontroller board and LabVIEW platform has been developed. \\
\hline & The proposed automated system has two hardware elements: the first one is a \\
\hline Accepted Jun 28, 2019 & $\begin{array}{l}\text { personal computer as a system main server hosting the designed LabVIEW } \\
\text { platform and the second element is a NI MyRIO microcontroller board for }\end{array}$ \\
\hline Keywords: & $\begin{array}{l}\text { managing the operating between the appliances and the sensors. } \\
\text { The appliances can be automatically monitored, controlled, and accessed in }\end{array}$ \\
\hline Hardware implementation & response to the signals from the related sensors or manually by the system \\
\hline Home automation approach & $\begin{array}{l}\text { end-user through smart phone based on } W_{1}-\mathrm{F} 1 \text { and cloud computing } \\
\text { technology. To approve the reliability of the proposed automated system, }\end{array}$ \\
\hline LabVIEW platform & a hardware realization for three appliances: temperature management, \\
\hline NI MyRIO microcontroller & light energy saving, and biometric security system of face recognition with \\
\hline Sensors & $\begin{array}{l}\text { fingerprint check has been introduced. The proposed system has a simple } \\
\text { structure, economically cost effective and flexible scaling up for a proper } \\
\text { automated home future. }\end{array}$ \\
\hline
\end{tabular}

Copyright ( 2019 Institute of Advanced Engineering and Science. All rights reserved.

\section{Corresponding Author:}

Ahmad A. Alahmadi,

Department of Electrical Engineering,

Faculty of Engineering, Taif University,

Taif 21974, Kingdom of Saudi Arabia.

Email: ahmadaziz66@ hotmail.com

\section{INTRODUCTION}

Recently, the rapid development in communications and information technologies has a big impact on the human life. Particularly, new technologies based on the Internet services become necessary in our daily routine life. Furthermore, portable devices including smart phones provide appropriate online access for them. For that, Internet of Things (IoT) technology will cause a dramatic impact in informational society for the human being's way of life. Specially, the upcoming $5 \mathrm{G}$ communication system will based on the internet of things technology which will not only cause comfortable and safe for the life but also can be a new strategy for energy management and saving problem [1-5].

Because of the rapid revolution in electronics inventions and their integration with conventional building industry, the idea of smart and intelligent home system has been adopted by many researchers and lifestyle professionals' companies. The first smart house concept was developed in 1980's as a project of the National Research Center of the National Association of Home Builders. The basic idea of smart home automation is to use sensors and control system technologies to monitor a home, and provide an adjustment for various services such as lighting, heat, ventilation, and other. Modern homes require to have numerous appliances for comfortable and luxury human life that cause increasing of the energy demand for operation. For that, smart home can achieve an intelligent and efficient energy management and saving through 
scheduling, monitoring, diagnostic, and controlling the appliances. Economically, lifelong of the appliances will be increased and the maintenance expenses will be reduced [6-9].

Remarkable efforts have been achieved for developing the smart home remote control systems. The earlier proposed systems are mainly a land phone-based system with personal computer approach for remote controlling some of home appliances [10-12] based on FPGA [13, 14]. These types of systems used the conventional land-phone for remotely controlling the system devices with the other subsystems connected through any user interface. Moreover, the growth of telecommunication technologies has impacted most of recent smart home automation industries employed the modern wireless communication technologies to communicate the home appliances. The latest designed systems using the new wireless approaches including RF, GSM, Bluetooth, Zig Bee ,... etc for short distance remote controlling the various appliances have been developed in [15-18]. The effective cost arranging network problem of objects for a green IoT is investigated by introducing a new unique deployment scheme for developing an IoT based green network approach. Also, the energy consumption and smart energy control framework for intelligent home approach is a hot topic to be considered [19-21]. A cloud based and Android system supported home automation approach for allowing multiple users to monitor and control many appliances using Android applications or through a web site is developed [22, 23]. Different Arduino modules for smart cellular phone was used to achieve the control function for the home appliances by employing the smartphone to point to the required appliances, the phone's monitor automatically pops out on the designed control panel of the device, the proposed scheme was verified through the simulation study and the on-site hardware realization successfully [24, 25].

This paper presented a design process and a hardware implementation for a wireless real-time home automation system approach based on NI MyRIO microcontroller board and LabVIEW platform. The developed automated system has two hardware elements: the first element is a personal computer acting a system main server hosting the designed LabVIEW platform, where the second element is a NI MyRIO microcontroller board for managing the operating between the appliances and the sensors. The appliances can be automatically monitored, controlled, and accessed in response to the signals from the related sensors or manually by the system end-user through smart phone based on Wi-Fi and cloud computing technology. The reliability of the proposed system is validated through a hardware implementation for three appliances: temperature management, light energy saving, and biometric security system of face recognition with fingerprint check.

The following sections of this paper is arranged as: Section 2 introduces the designing process and the system structure. The proposed system hardware on-site implementation is developed in Section 3. Finally, the conclusion part is addressed in Section 4.

\section{PROPOSED SYSTEM STRUCTURE AND DESIGNING ALGORITHM}

The proposed smart automated system has two principle hardware components: the PC home server and the NI MyRIO microcontroller board that can be connected to computer via Wi-Fi and communicates using standard serial protocol. The architecture of the system developed is shown in Figure 2. 12 a PC home server hosts the LabVIEW platform management and control algorithm that enables the user to access the home appliances through it. Many appliances and sensors are connected to ports of the microcontroller board. The home appliances can be controlled automatically or accessed manually through the system user. The essential part of the proposed automated home system includes the NI MyRIO microcontroller board which is connected with a number of sensors and appliances actuators. A personal computer acting as a system server for hosting the LabVIEW management algorithms of the appliances operation is connected to the microcontroller via Wi-Fi wireless technology. The appliances can be automatically monitored, controlled, and accessed in response to the signals from the related sensors or manually by the system enduser through smart phone based on Wi-Fi and cloud computing technology as shown in Figure 1.

In this design, three different appliances including temperature control, light control, and biometric based security sub-system have been developed. The flow charts of these three appliances algorithms are shown in Figure 2. In case of temperature control process, temperature sensor measures the ambient temperature. The microcontroller will compare the sensor reading with a reference temperature $\left(30^{\circ} \mathrm{C}\right.$ set as a reference temperature). For automatic control case, if the temperature exceeds $30^{\circ} \mathrm{C}$, microcontroller will operate the air-condition to reduce the temperature level as shown in Figure 2 (a). In automatic light management algorithm, an object motion detection sensor is employed. In case of human movement, the light will be in on-state on for five minutes and recheck the object status again as shown in Figure 2(b). This application is very useful for energy saving and management. Figure 2 (c) shows the algorithm used for biometric based sub-system for the automated home system security. There are two security access levels including face recognition utility and fingerprint check. moreover, all the three algorithms mentioned above 
can be manually managed by the system end-user through monitoring and controlling processes via wireless portable devices like laptops, cellular phones and tablets.

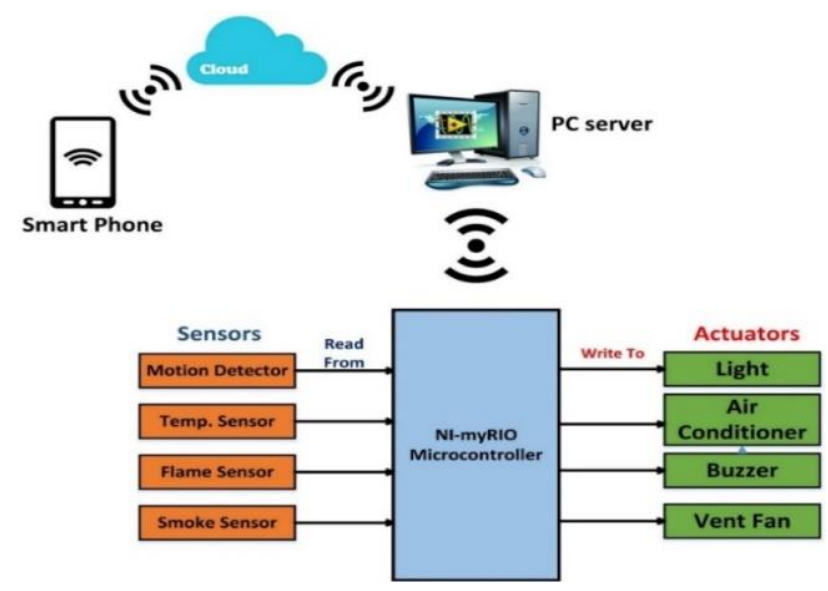

Figure 1. Structure of the automated home system

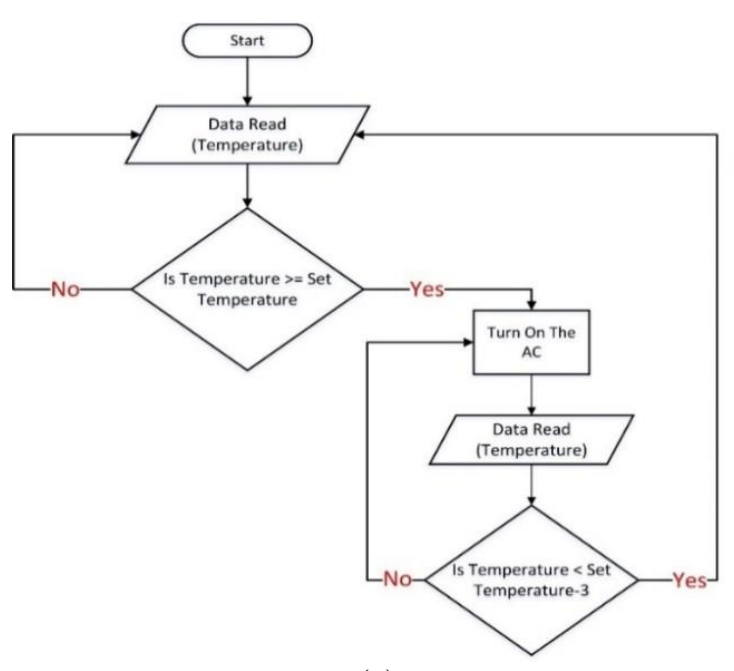

(a)

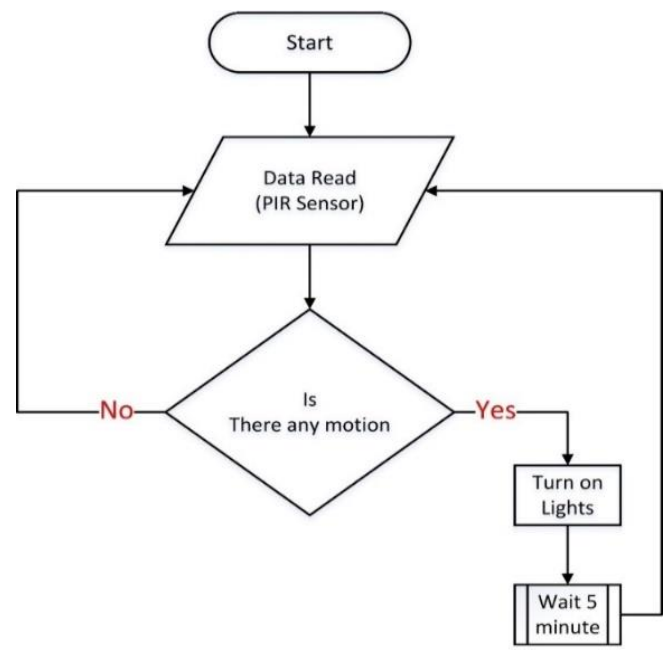

(b)

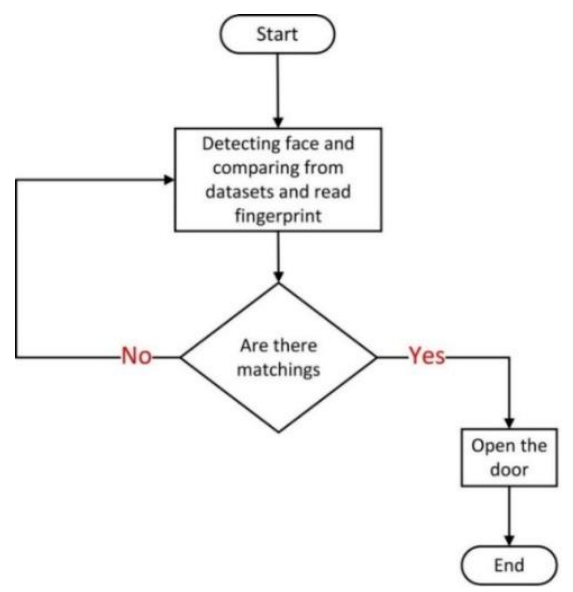

(c)

Figure 2. Flow charts of the automated home system processes (a) Temperature control; (b) Light control; (c) Biometric security sub-system 


\section{ON-SITE EXPERIMENTAL RESULTS AND DISCUSSION}

To justify the proper operation of the designed system, an on-site hardware implementation has been developed on-site (Lab room in the faculty building) as shown in Figure 3. The system includes a personal computer as system server with LabVIEW platform management algorithm (block diagram detailed in Figure 4) and the MyRIO microcontroller board that enables the control processes for different home appliances. A three different types of home appliances and sensors are connected to the microcontroller board. Miscellaneous home appliances can be controlled automatically or accessed through the system enduser. The main sever computer is connected to the MyRIO microcontroller via Wi-Fi. The three employed sensors are: LM35 temperature sensor for air-condition temperature management, Passive Infrared (PIR) sensor for human motion detection utilized for light control process, and a biometric based sub-system for the system security including face recognition utility and fingerprint check as shown in Figure 5.

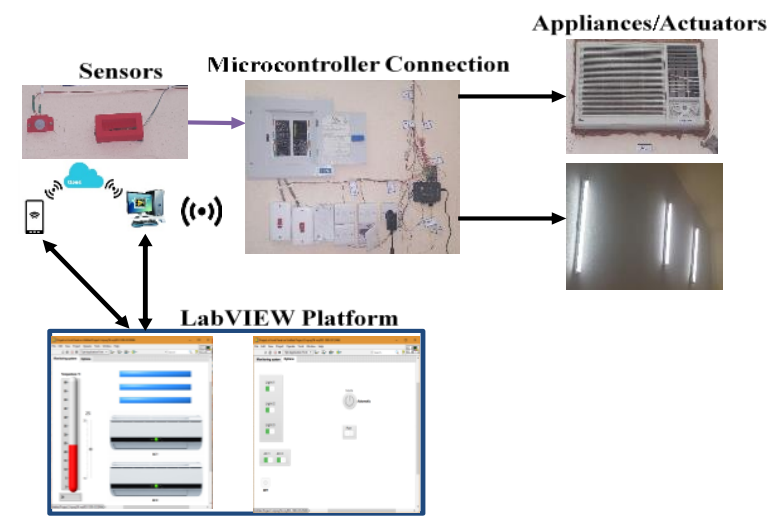

Figure 3. Proposed automated home hardware realization

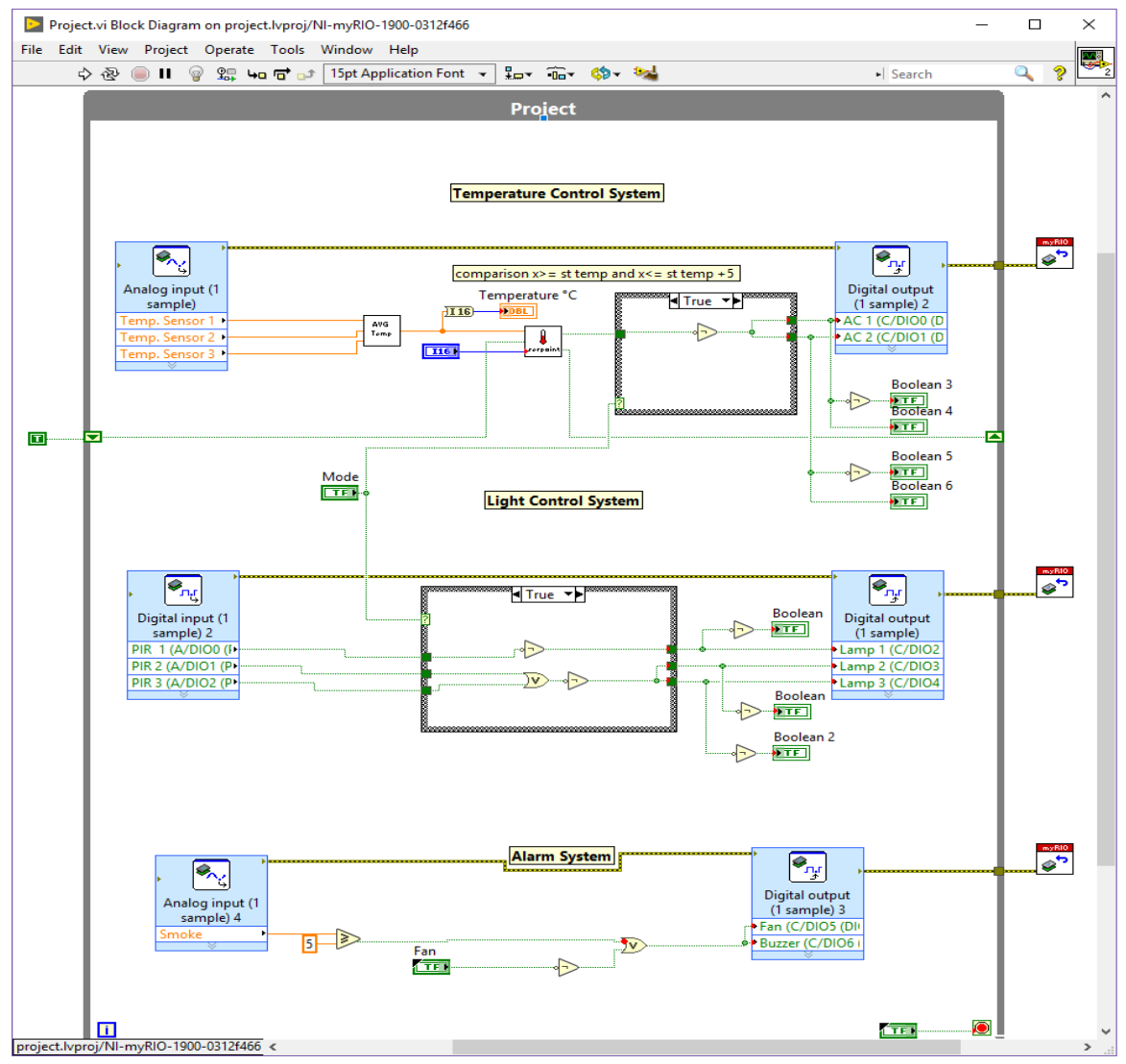

Figure 4. Block diagram of the proposed LabVIEW management platform 


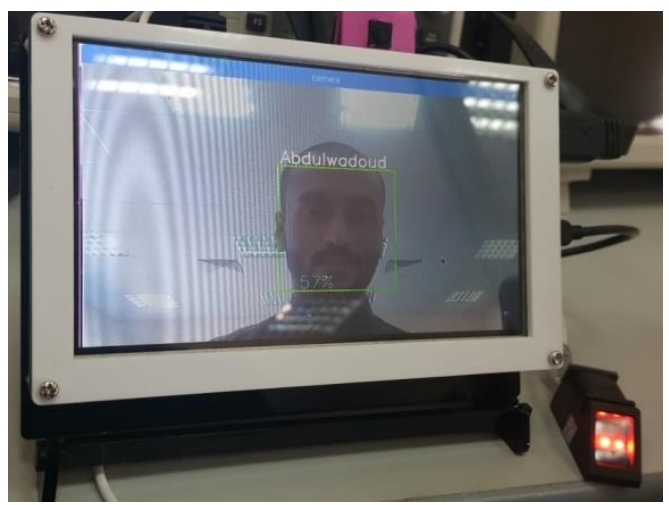

Figure 5. The biometric based security sub-system with face recognition utility and fingerprint check

\section{CONCLUSION}

This paper presented a design process and a hardware implementation for a real-time wireless automated home system approach utilizing NI MyRIO microcontroller board and LabVIEW platform. The proposed automated system has two hardware elements: the first one is a personal computer as a system main server hosting the designed LabVIEW platform and the second element is a NI MyRIO microcontroller board for managing the operating between the appliances and the sensors. The appliances can be automatically monitored, controlled, and accessed in response to the signals from the related sensors or manually by the system end-user through smart phone based on Wi-Fi and cloud computing technology. The reliability of the proposed system has been verified thought on-site hardware realization for three essential appliances: temperature management, light energy saving, and biometric security system of face recognition with fingerprint check has been introduced. The developed system has a simple structure, economical cost and flexible configuration with scaled up feature. A future improvement can be developed to the proposed system scheme using wireless sensors for internet of things approach.

\section{REFERENCES}

[1] A. Zanella, N. Bui, A. Castellani, L. Vangelista and M. Zorzi, "Internet of Things for Smart Cities," IEEE Internet of Things Journal, vol. 1, no. 1, pp. 22-32, Feb. 2014.

[2] Liu, Chien-Yuan Juang, "A Smart Home Automation System," in Proceedings of the 3rd Intenational Conference on Intelligent Technologies and Engineering Systems (ICTES2014), vol. 345 of the series Lecture Notes in Electrical Engineering, pp 381-388, Springer, 2014.

[3] Aggarwal, Charu C., Ashish, Naveen, Sheth, Amit "The Internet of Things: A Survey from the Data-Centric Perspective -Managing and Mining Sensor Data," pp 383-428, pringer, 2012.

[4] J. A. Stankovic, "Research Directions for the Internet of Things," IEEE Internet of Things Journal, vol. 1, no. 1, pp. 3-9, Feb. 2014.

[5] Biljana L. Risteska Stojkoska, and Kire V. Trivodaliev, "A Review of Internet of Things for smart home: Challenges and solutions," Journal of Cleaner Production, vol.140, part 3, pp.1454-1464, Jan. 2017.

[6] Nicoleta Arghira, Lamis Hawarah, Stéphane Ploix, and Mireille Jacomino, "Prediction of Appliances Energy Use in Smart Homes," Energy, vol. 48, iss. 1, pp. 128-134, Dec. 2012.

[7] Gayathri N., Vineeth V.V., and N. Radhika, "A Novel Approach in Demand Side Management for Smart Home," Procedia Technology, Elsevier Ltd., vol. 21, pp. 526-532, 2015.

[8] Prashant Kumar, Claudio Martani, Lidia Morawska, Leslie Norford, Ruchi Choudhary, Margaret Bell, and Matt Leach, "Indoor Air Quality and Energy Management Through Real-Time Sensing in Commercial Buildings," Energy and Buildings, vol. 111, pp. 145-153, Jan. 2016.

[9] Mohammad Ali Fotouhi Ghazvini, João Soares, Omid Abrishambaf, Rui Castro, and Zita Vale, "Demand Response Implementation in Smart Households," Energy and Buildings, vol. 143, pp.129-148, May 2017.

[10] Yang, Shuang-Hua, "ZigBee Smart Home Automation Systems-Wireless Sensor Networks: Principles, Design and Applications," Springer-Verlag London, 2014.

[11] Amirah Aisha Badrul Hishama, Mohamad Hafis Izran Ishaka, Chan Kok Teika, Zaharuddin Mohameda, and Nurul Hawani Idrisb, "Bluetooth-Based Home Automation System Using an Android Phone," Jurnal Teknologi (Sciences \& Engineering), vol.70, no.3, pp.57-61, 2014.

[12] Bader M. O. Al-thobaiti, Iman I. M. Abosolaiman, Mahdi H. M. Alzahrani, Sami H. A. Almalki, and Mohamed S. Soliman, "Design and Implementation of a Reliable Wireless Real-Time Home Automation System Based on Arduino Uno Single-Board Microcontroller" International Journal of Control, Automation and Systems, vol. 3, no.3, pp. 11-15, Jul. 2014. 
[13] Iman I. M. Abu Sulayman, Sami H. A. Almalki, and Mohamed S. Soliman, "Designing a Reliable Dual Modes Real-Time Home Automation System Based on Very High Speed Description Language," International Journal of Control, Automation and Systems, vol.5, no.3, pp. 19-23, Jul. 2016.

[14] Chee-Pun Ooi, Wooi-Haw Tan, Soon-Nyean Cheong, Yee-Lien Lee, V. M. Baskaran, and Yeong-Liang Low, "FPGA-based embedded architecture for IoT home automation application," Indonesian Journal of Electrical Engineering and Computer Science, vol. 14, no. 2, pp. 646-652, May 2019.

[15] Mahesh N. Jivani, "GSM Based Home Automation System Using App-Inventor for Android Mobile Phone," International Journal of Advanced Research in Electrical, Electronics and Instrumentation Engineering, vol. 3, no. 9, pp.12121-12128, Sept. 2014.

[16] Cong Hui Huang, Yih Feng Su, Yu Tang Su, Wei Hao Su, Jun Jie Chen, and Wei Jie Zhou, "Design and Application of ZigBee Wireless Techniques for an Intelligent House Lighting Control System," in International Symposium on Computer, Consumer and Control 2014, Tiwan pp. 19 - 22, 2014.

[17] D. Naresh, B. Chakradhar, and S. Krishnaveni, "Bluetooth Based Home Automation and Security System Using ARM9," International Journal of Engineering Trends and Technology, vol. 4, no. 9, pp. 4052- 4058, Sep. 2013.

[18] S. R. Bharanialankar and C. S. Manikanda Babu, "Intelligent Home Appliance Status Intimation Control and System Using GSM," International Journal of Advanced Research in Computer Science and Software Engineering, vol. 4, No. 4, pp.554-556, Apr. 2014.

[19] J. Huang, Y. Meng, X. Gong, Y. Liu and Q. Duan, "A Novel Deployment Scheme for Green Internet of Things," IEEE Internet of Things Journal, vol. 1, no. 2, pp. 196-205, April 2014.

[20] J. Pan, R. Jain, S. Paul, T. Vu, A. Saifullah and M. Sha, "An Internet of Things Framework for Smart Energy in Buildings: Designs, Prototype, and Experiments," IEEE Internet of Things Journal, vol. 2, no. 6, pp. 527-537, Dec. 2015.

[21] S. D. T. Kelly, N. K. Suryadevara, and S. C. Mukhopadhyay, "Towards the Implementation of IoT for Environmental Condition Monitoring in Homes," IEEE Sensors Journal, vol. 13, no. 10, pp. 3846-3853, Oct. 2013.

[22] Ilker Korkmaz, Senem Kumova Metin, Alper Gurek, Caner Gur, Cagri Gurakin, and Mustafa Akdeniz, "A Cloud Based and Android Supported Scalable Home Automation System," Computers and Electrical Engineering, vol. 43, pp. 112-128, Apr. 2015.

[23] R. MF. Amin, R. F.A Yasmin, A. N. Azlina, AB. Zanariah, and Y. Faridah, "Intelligent home automated system," Indonesian Journal of Electrical Engineering and Computer Science, vol. 15, no. 2, Aug. 2019.

[24] M. S. Pan and C. J. Chen, "Intuitive Control on Electric Devices by Smartphones for Smart Home Environments," IEEE Sensors Journal, vol. 16, no. 11, pp. 4281-4294, June 2016.

[25] Bouzid Mohamed Amine, Chaib Fatima Zohra, Hamani Ilyes, Aid Lahcen, and Allaoui Tayeb, "Smart Home Automation System based on Arduino," International Journal of Robotics and Automation (IJRA), vol.7, no.4, pp. 215-220, Dec. 2018.

\section{BIOGRAPHIES OF AUTHORS}

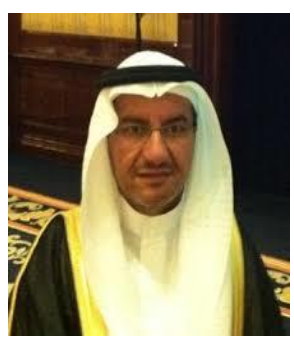

Ahmad A. Alahmadi: An associate professor in the department of Electrical Engineering, Faculty of Engineering, Taif University, Saudi Arabia. Since July 2017, Dr. Alahmadi became the Vice-Dean of the Faculty of Engineering, Taif University, Saudi Arabia. His research interests include nano-sensors and smart cities approaches. 